\title{
OS DESAFIOS E AS POSSIBILIDADES DE UM GRUPOMULTIDISCIPLINAR NA CRIAÇÃO DE UM SETOR DE EDUCAÇÃO A DISTÂNCA*
}

\author{
Elisa Netto Zanette \\ Universidade do Extremo Sul Catarinense - enz@unesc.net \\ Cleusa Ribeiro dos Santos \\ Universidade do Extremo Sul Catarinense - csa@unesc.net \\ Graziela Fátima Giacomazzo Nicoleit \\ Universidade do Extremo Sul Catarinense - gfg@unesc.net \\ Patricia Jantsch Fiuza \\ Universidade do Extremo Sul Catarinense - pjf@unesc.net
}

\begin{abstract}
Resumo: Neste artigo apresenta-se a experiência vivenciada por um grupo multidisciplinar na implantação da Educação a Distância $(\mathrm{EaD})$ no ensino superior. Os primeiros debates e reflexões acerca da educação a distância iniciaram em 2000, objetivando pesquisar sobre a viabilidade e implementação dessa modalidade de Educação na Universidade do Extremo Sul Catarinense (Unesc). As reflexões fundamentaram-se no Projeto Político Pedagógico, na missão, cultura e características da Instituição baseando-se em uma concepção pedagógica clara e definida visando à constituição de um espaço acadêmico de planejamento, gerenciamento e avaliação dos projetos em $\mathrm{EaD}$, em consonância com a legislação nacional vigente e os diversos órgãos instituídos na Unesc. Esse propósito evidenciou a necessidade de outras competências que foram sendo desenvolvidas no processo, envolvendo desde a resignificação de paradigmas, a definição de possibilidades de desenvolvimento de materiais didáticos privilegiando a construção coletiva e optando pelo uso de mídias agregadas. A experiência na construção colaborativa e cooperativa do modelo pedagógico, da escolha das teconologias e da estrutura administrativa permitiu a evolução dos projetos a partir dos desafios, da busca da superação das dificuldades, das soluções construídas pelo grupo podendo subsidiar futuras propostas de implantação de EaD no Ensino Superior.
\end{abstract}

Palavras-chave: Educação a Distancia; Equipe Multidisciplinar; Implementação; Educação Superior.

Abstract: The present article aims at presenting the experience of a multidisciplinary team introducing Distance Education to Higher Education. The first debates and reflections about Distance Education took place in the year 2000, with the objective of doing research about the viability and implementation of such an education modality at UNESC (Universidade do Extremo Sul Catarinense, Criciúma - SC). The reflections were based on the pedagogical Political Project as well as on the mission of the Institution, its culture and characteristics, having a definite and clear pedagogical

* Artigo em inglês submetido e apresentado na $22^{\text {a }}$ Conferência Mundial do Conselho Internacional de Educação Aberta e a Distância - ICDE realizado no io de Janeiro em setembro de 2006. 
conception, aiming at creating an academic space for planning, management, and evaluation of Distance Education projects, according to current national legislation and the several sectors set up at UNESC. This purpose showed the necessity of other competences which were defined during the process, even involving paradigms resignificance, and the definition of teaching materials development possibilities, favoring collective construction and opting for associated media use. The definition of the learning virtual environment was based on free software conceptions, trying to enlarge the institutional research space. This process strengthened the continuing education programs concerning of the dissemination of the technology use in the distance and presence education. The experience, which was obtained during the process, permitted the projects to evolve from challenges, from difficulties that were overcome, and from the solutions constructed by the group together what may underlie future introduction proposals for Distance Education to Higher Education.

Keywords: Distance Education; Multidisciplinary Team; Implementation; Higher Education.

\section{INTRODUÇÃO}

A crescente demanda pela educação e a necessidade constante de formação contínua, pessoal e profissional nas diferentes instâncias vem sinalizando ao sistema de ensino presencial superior a necessidade imprescindível à sociedade contemporânea de inserção da educação nas suas diferentes formas e modalidades. Em virtude disso, esse processo se fortaleceu na educação brasileira com a regulamentação da Educação a Distância $(\mathrm{EaD})$ em legislação nacional.

Por sua vez, o desenvolvimento acelerado das Tecnologias de Informação e Comunicação (TICs) e de Gestão ampliou de forma significativa as possibilidades e a diversidade de oferta de modalidades híbridas de ensino nas Instituições de Ensino Superior (IES). Ressignificada na contemporaneidade, estas modalidades de Educação provocaram o surgimento dos Centros, Setores e Núcleos de EaD.

A Universidade do Extremo Sul Catarinense (Unesc) se insere neste contexto e busca continuamente propiciar ambientes de aprendizagem que contribuam com a formação de sujeitos autônomos, críticos, reflexivos, atuantes e transformadores, visando a promoção e o desenvolvimento da qualidade do ambiente de vida. Localizada no extremo sul do estado de Santa Catarina, constitui-se como uma IES fortalecida na presencialidade dos seus alunos em seus cursos. Atua no âmbito da Graduação, Pós- Graduação lato e stricto sensu, Extensão e Colégio de Aplicação.

Relata-se, neste artigo a experiência de profissionais da educação, envolvidos no processo de constituição institucional do Setor de Educação a Distância (Sead) da IES, objetivando a reflexão sobre a prática.

\section{A CONSTITUIÇÃO DO GRUPO DE TRABALHO EM EDUCAÇÃO A DISTANCIA: BREVE HISTÓRICO}

Os primeiros estudos sobre a $\mathrm{EaD}$ na Unesc surgiram do interesse da IES em promover estudos sobre essa modalidade de ensino e avaliar a viabilidade e implementação da mesma no contexto didático/pedagógico.

A proposta emergiu em 2000, por iniciativa e reflexões empreendidas na IES no âmbito da Pró-Reitoria de Ensino, constituída por um grupo multidisciplinar de estudo, formado inicialmente por docentes vinculados aos cursos de licenciatura. Este movimento se fortaleceu com a constituição nacional de consórcios entre IES visando 
a democratizar o acesso à educação de qualidade por meio da oferta de cursos a distância.

O desafio da implantação do projeto em âmbito estadual provocou o movimento nas IES de reflexão sobre a prática, ao executar e avaliar o processo de gestão, tutoria e monitoria do referido curso. Esse projeto orientou os primeiros debates acerca da modalidade de $\mathrm{EaD}$ na Unesc que se ampliaram à medida em que as pesquisas e estudos desenvolvidos foram fortalecendo-se.

A demanda para novos cursos no âmbito de aperfeiçoamento e extensão provocou a necessidade de ampliação do grupo multidisciplinar e de espaço físico para a constituição de um ambiente acadêmico de planejamento, gerenciamento e (re)avaliação da demanda em EaD, em consonância com a legislação nacional.

Neste processo, emergiu, também, a necessidade de políticas de efetivação da inserção das tecnologias no contexto educacional, presencial e a distância e o fortalecimento da cultura de EaD na IES. As ações de inserção das tecnologias informáticas nas práticas pedagógicas, tinham, até então, alcance limitado a alguns cursos da Graduação. Optou-se, então, em 2002, pela adoção de um Ambiente Virtual de Aprendizagem (AVA) que possibilitasse o fortalecimento dos espaços de pesquisa e adequação ao contexto didático/pedagógico da IES, definido em seu Plano Político e Pedagógico (PPP).

A implantação e utilização do AVA, como instrumento pedagógico, provocou a necessidade de superação de diversos obstáculos, desde a instalação e adequação dos recursos à formação dos professores e alunos no uso pedagógico do mesmo; problemas iniciais de infra-estrutura foram se adequando ao contexto e, gradativamente, resolvidos. Finalmente a formação continuada dos professores no uso do AVA e das mídias agregadas iniciou em 2002.

Os processos de organização, planejamento, execução e avaliação de projetos em $\mathrm{EaD}$, agregando mídias diversas como o AVA, fomentaram a ampliação do grupo de estudo para grupo de pesquisa, consolidando-se como grupo de trabalho, instituído na informalidade como Setor de Educação a Distância.

Esta organização provocou, além da necessidade institucional de criação do setor, o encontro dos profissionais que foram agregando-se por projetos. $\mathrm{O}$ trabalho de cooperação e colaboração foi bastante evidenciado, pois como cita Okada (2003, p.16)

"quando os sujeitos interagem e trabalham colaborativamente, constroem conhecimento de modo mais significativo, desenvolvem habilidades intra e interpessoais, deixam de ser dependentes para se independentes". Tal momento possibilitou trocas, experiências, incertezas, curiosidades em busca do novo naquele espaço do desconhecido. Sabe-se que os sujeitos, ao depararem-se com situações novas, são envolvidos em sentimentos diversos, pela incerteza de não saber ainda mapear o traçado de uma caminhada. Então, no referido processo, são muitas as vivências e os desafios internos e externos.

Os desafios internos estão relacionados com a história individual de aprendizagem de cada integrante do grupo, que historicamente se constitui na presencialidade de quem ensina e de quem aprende.

Os desafios externos mostram-se sempre os mais complexos, pois, determinados pelas idéias coletivas, criam as resistências quanto às mudanças com resistências positivas e negativas. Já as resistências negativas surgem para negar, rechaçar, excluir, sem ao menos conhecer de fato a proposta. Estas são as que limitam o processo, fazem emergir banalizações, generalizações que acabam afetando todo o 
esforço coletivo de trabalho, estudos e dedicação, pelo simples fato de não conseguir internamente vencer seus próprios desafios.

Nessa caminhada, formar uma massa crítica torna-se essencial para alavancar um setor ou núcleo que se propõe a fazer Educação a Distância numa instituição de ensino superior. As ações provenientes dessa intenção, opção da equipe deste relato, objetivaram agregar profissionais interessados em conhecer a modalidade. Neste sentido, as cooperações por adesão nos projetos desenvolvidos garantem $\mathrm{O}$ comprometimento, a dedicação, a qualidade e a credibilidade. A partir disso, profissionais de diversas áreas da IES foram se agregando aos projetos, fortalecidos também pelo acesso aos cursos de formação permanente promovidos pelo Sead, objetivando o uso dos recursos tecnológicos na educação, independente da modalidade de ensino.

O grupo constituído organizou o seu trabalho na modalidade de Educação a Distância levando em conta a missão da Instituição e a sua cultura, a concepção pedagógica definida no PPP da IES e dos cursos. Este movimento possibilitou o encontro de idéias subsidiando a construção dos projetos, o que reflete em todo o processo, desde a seleção das mídias e/ou ambiente de aprendizagem. até a concepção pedagógica dos cursos.

Neste cenário, o Sead passou da informalidade para a institucionalização em 2003, regulamentado em portaria por órgão competente da IES, validando as ações até então desenvolvidas e reafirmando a intencionalidade de atuação nessa modalidade de educação. O Sead, como uma unidade vinculada à Pró-Reitoria de Ensino, consolida- se como setor responsável pela proposição, produção, difusão, gestão e avaliação de projetos e experiências inovadoras em Educação a Distância (EaD). Composto por uma equipe multidisciplinar representativa das diversas áreas de conhecimento foi concebido em consonância com a missão da Unesc que propunha, na época Promover o desenvolvimento regional para melhorar a qualidade do ambiente de vida e implementado em função das necessidades sociais de formação e capacitação de profissionais de diversas áreas, utilizando as tecnologias de comunicação e informação, como um recurso para o aprender a distância. O Sead, em suas ações de formação discente e docente representa uma estratégia da Instituição na insersão das tecnologia na educação e na democratização, acesso e permanência dos estudantes visando à melhoria da qualidade de educação.

As experiências pedagógicas desenvolvidas na modalidade de $\mathrm{EaD}$, próprias e/ou em parceria com outras Instituições, no período de 2000 a 2003, coordenadas pelo Sead, permitiram a concretização do processo de credenciamento da IES na pósgraduação lato sensu. Viabilizaram, também, a execução de novas ações com o estudo e a elaboração de novos projetos.

$\mathrm{O}$ interesse dos docentes em conhecer e utilizar as propostas de $\mathrm{EaD}$ e a procura por informações a respeito de disciplinas da graduação e cursos nesta modalidade de educação tem aumentado de forma considerável por acadêmicos e pessoas da comunidade.Atualmente, o Sead desenvolve projetos de extensão e aperfeiçoamento, disciplinas na graduação e curso de Pós-Graduação lato sensu na modalidade semipresencial e a distância. Integra-se no desenvolvimento dos projetos o Departamento de Tecnologia da Informação, as Diretorias de Extensão, de Graduação

Pós, os Cursos de Graduação e demais setores necessários. Os projetos de cursos e/ou disciplinas na modalidade de $\mathrm{EaD}$ que necessitam de produção de material de multimídia são desenvolvidos em parceria com os profissionais especialistas em multimídia do Departamento de Tecnologia de Informação. Nesta 
mesma forma de parceria, acontecem as atividades de pesquisa, desenvolvimento e manutenção de outros recursos tecnológicos como o Ambiente Virtual de Aprendizagem da Instituição (Learnloop). A participação da Unesc nos Consórcios UniVirtual-SC e Consórcio ACAFEVirtual, formado por todas as IES do Sistema ACAFE, concretiza-se pelo Sead.

\section{PRINCÍPIOS NORTEADORES DO SEAD}

Para a realização de projetos em $\mathrm{EaD}$, foram listados alguns princípios norteadores que envolvem a compreensão dos marcos conceituais e a reflexão sobre os componentes epistemológicos, as abordagens e as estratégias para viabilizar projetos nessa modalidade. Os princípios norteadores se situam, de acordo com Gutierrez (apud LANDIM, 1997) e Oliveira (2001) em: democratização, individualização, autonomia, comunicação, socialização, abertura, criatividade, educação permanente e flexibilidade.

Como princípios instituídos para a sustentação dos projetos na modalidade de EaD no SEAD da Unesc, tem-se: diversidade; autonomia; investigação; relação teoria e prática; trabalho cooperativo e colaborativo; dialogicidade; construção e reconstrução do conhecimento; interatividade e criticidade.

Neste contexto, inserem-se a proposição de diretrizes, parâmetros e metas para o desenvolvimento da EaD em parceria com as Diretorias e Cursos, visando promover a ampliação de oportunidades educativas, de modo especial para as pessoas que não puderam iniciar ou concluir seus estudos. Como cita Martins (1995), dessa forma, educandos dispersos geograficamente e residentes em locais onde não haja instituições convencionais de ensino têm acesso a novos conhecimentos com professores altamente qualificados.

Esses princípios norteadores promovem a permanência dos educandos no seu meio cultural e natural, evitando êxodos que incidem negativamente no desenvolvimento regional e propiciam o desenvolvimento de atividades de aprendizagem a partir das experiências dos educandos, as suas vidas profissionais e sociais, sem afastamento de seus locais de trabalho.

Assim, os projetos de $\mathrm{EaD}$ desenvolvidos, no Sead, em parceria com os órgãos instituídos da Unesc, devem considerar os projetos pedagógicos, as diretrizes curriculares, a flexibilização e o processo de ensino aprendizagem. O processo de comunicação bidirecional e multidirecional é relevante nesses projetos, pois, como define Neder (2000, p.118), representa "a comunicação na modalidade interativa entre professor $\mathrm{x}$ estudante e, entre todos os sujeitos do processo, no sentido da participaçãointervenção".

Neste contexto, o professor é o organizador de situações de aprendizagem. Esta preocupação evidencia-se, também, no planejamento do material didático e nas mídias utilizadas. Os materiais são planejados de forma minuciosa com a elaboração de recursos didáticos por profissionais de diferentes áreas de conhecimento, de comprovada competência, visando à garantia da qualidade do processo de ensino e aprendizagem.

Busca-se, ainda, a avaliação permanente do próprio sistema, compreendido como estruturas organizacionais que possibilitam a oferta da modalidade de Educação a Distância. Avaliar esse sistema se faz necessário para diagnosticar, analisar e mensurar o alcance dos objetivos da IES e dos cursos em EaD. Na Unesc, esse processo tem o acompanhamento do Setor de Avaliação Institucional.

Para a eficiência desses processos, faz-se necessário, também, propiciar a oferta de estratégias e recursos adequados para a formação permanente e para o 
aperfeiçoamento dos profissionais envolvidos. Então os professores são capacitados para as funções de autoria e tutoria, com suporte didático-pedagógico e tecnológico na produção de materiais e a toda sistemática operacional para a modalidade de EaD.

\section{CONCEPÇÃO PEDAGÓGICA NORTEADORA}

A Educação à Distância é compreendida como uma modalidade de educação que pode, ao lado de outras modalidades, contribuir decisivamente para ampliar o acesso ao conhecimento.

A concepção de $\mathrm{EaD}$ adotada pelo Sead insere-se numa proposta pedagógica que se sustenta no reconhecimento da educação como um sistema aberto que considera o ser humano em sua multidimensionalidade. Nesta perspectiva, o ponto de partida de todo o processo ensino aprendizagem deve ser a realidade sócio-histórica do indivíduo, incluindo a compreensão da complexidade do conhecimento e de seu processo de construção.

Conforme afirma Niskier (1999), ter claro a teoria de aprendizagem que embasa os projetos nessa modalidade pode trazer uma boa contribuição, principalmente quando o professor não deseja simplesmente transpor sua prática presencial para a distância, nem apenas fazer concessões para o estudante aprender sozinho, mas está disposto a redimensionar a própria significação do que é ensinar e aprender.

Parte-se, portanto, do pressuposto que o processo de aprendizagem é dinâmico, social e individual, pois cada sujeito constrói o seu próprio percurso de desenvolvimento a partir da interação com o outro, com os objetos e com a natureza. Nesse sentido, entende-se que os instrumentos tecnológicos potencializam a interação entre professor, educando e conhecimento e, conseqüentemente, o processo ensino aprendizagem. Ao utilizar-se de novas tecnologias que potencializam o ensino aprendizagem, a instituição cumpre sua função social e possibilita a formação da cidadania.

Por suas características, a Educação a Distância permite avançar de uma compreensão de educação como sistema fechado, voltado para a transmissão e transferência, para um sistema aberto, implicando processos transformadores que decorrem da experiência de cada um dos sujeitos da ação educativa.

Essa modalidade exige troca, diálogo e interação entre os sujeitos da ação pedagógica, reintegrando o educando como sujeito da construção do conhecimento. No contexto atual, o conhecimento evolui de forma intensa e exige uma educação voltada para a autonomia do aprendiz, o que implica uma metodologia do aprender a aprender, com suporte na produção do conhecimento pela pesquisa e investigação. Logo a autonomia do educando passa a ser um dos ideais da ação educativa, porque ele é desafiado a construir sua autonomia frente ao processo de aprendizagem, instigado a buscar e a ser ativo no processo de construção do conhecimento.

A EaD é uma modalidade que exige do educando um maior envolvimento e compromisso com a produção do conhecimento. Nesse enfoque, o currículo é algo em processo, flexível, aberto, concebido como resultado da ação e da interação dos sujeitos do ato educativo com a realidade. Esse modelo de educação transcende uma concepção fragmentada e compartimentalizada do conhecimento, para o desenvolvimento dos conceitos e teorias trabalhadas em uma abordagem construtivista.

No enfoque de processos interativos e dialógicos, a $\mathrm{EaD}$ fundamenta-se nas possibilidades de uso pedagógico das TICs atuais, que permitem não só novas e diferenciadas relações entre os sujeitos do processo educativo, mas também que a 
aprendizagem ocorra mediante processo de ação-reflexão-ação. A EaD utiliza recursos interativos de aprendizagem e dinamiza, da maneira mais atrativa e enriquecedora, o relacionamento professor-educando-conhecimento para que, mediado pelo professor orientador e/ou tutor, o educando possa aprender individualmente acompanhando seu próprio processo de aprendizagem.

A relação educador e educando se modifica sensivelmente na $\mathrm{EaD}$, visto que o professor passa a ser também aprendiz. Para Maia (2002, p.12), "não há diferença entre o professor presencial, virtual ou semipresencial". Ou seja, a mudança está nos papéis que devem ser adequados ao contexto do processo em que se desenvolve a aprendizagem. Se a aprendizagem decorre da interação entre os sujeitos, o professor passa a ter um novo papel no processo ensino-aprendizagem. Preocupado com a atualização constante, passa a ser um sujeito mais pesquisador do que transmissor, reconhecendo em seus educandos e também nos parceiros tutores potenciais interlocutores na produção de conhecimentos. Logo cabe ao professor, na $\mathrm{EaD}$, criar ambientes de aprendizagem que oportunizem o desenvolvimento da criatividade, da investigação, da resolução de problemas e do desenvolvimento do senso crítico.

Nesta perspectiva, o processo de aprendizagem insere-se na realidade cultural e contextualizada em que a compreensão dos objetos e dos eventos está diretamente ligada à forma na qual ela se produz. Assume-se a educação presencial e a educação a distância como um palco em que as significações são coletivamente produzidas e particularmente apropriadas, como também constituídas nas relações de aprendizagem, que o aprendiz estabelece com outros aprendizes e educadores um movimento dialético que compreende o social e o particular.

A EaD oportuniza, ainda, o trabalho coletivo que intersecciona os saberes de diferentes profissionais. Ela envolve no processo ensino-aprendizagem o professorautor, o educando e o orientador de aprendizagem, além de exigir também o trabalho compartilhado na ação do planejamento, desenvolvimento e avaliação de suas ações, com participação de especialistas em várias áreas como: informática, comunicação, educação, etc.

A proposta pedagógica da $\mathrm{EaD}$, inserida em um contexto de uso das diferentes mídias, oferece novos campos de desenvolvimento de competências atuais (PERRENOUD, 2000) e aumenta o alcance das desigualdades no domínio das relações sociais, da informação e do mundo. É a educação concebida como o elemento-chave na construção de uma sociedade baseada na informação, no conhecimento e no aprendizado.

Assim, busca-se uma cultura de educação que rompa com um ciclo determinado e que seus objetivos sejam fundamentados na democratização do saber, facilitando o acesso à escola, evitando a substituição desnecessária de sistemas presenciais por sistemas a distância, mas buscando formas de complementação em que um sistema contribui com o outro, visando à melhoria da qualidade educacional na formação de sujeitos críticos e atuantes.

\section{A GESTÃO DE SISTEMAS DE EAD NO SEAD}

O desenvolvimento da Educação a Distância, nas duas últimas décadas, caracterizou-se pela incorporação em sua base material das TICs. Nesse intuito, os diferentes sistemas de Educação a Distância incorporaram as contribuições desta geração tecnológica em seus sistemas pedagógicos e administrativos. Os sistemas pedagógicos e administrativos são sistemas aglutinadores de diferentes ações, políticas, infra-estrutura e concepção epistemológico-pedagógico da Universidade e compõe-se de gestão de pessoas, recursos físicos e estrutura tecnológica. 
A implementação da EaD no ensino cria novos sujeitos e redefine papéis, os quais requerem uma política de formação das pessoas para atuar nas diferentes dimensões, níveis ou sub-sistemas dessa modalidade de educação. Essa formação sólida e urgente deverá capacitar o quadro docente dos diferentes departamentos e setores da universidade em todos os níveis, bem como propiciar o desenvolvimento da cultura de EaD.

Faz-se necessária, também, a formação de uma equipe multidisciplinar de professores/pesquisadores das diversas áreas do conhecimento com ênfase, interesse $\mathrm{e}$ estudos sobre $\mathrm{EaD}$ e os seus meios mediatizadores. A organização dessa equipe deve atender as funções mínimas de: coordenação geral do Sead, professores, monitores, secretaria, suporte técnico e apoio para produção de material.

A organização da estrutura física deve vir ao encontro das condições e necessidades que irão garantir a qualidade desta modalidade. Entende-se como necessário disponibilizar espaço físico para recepção, sala de monitoria e tutoria, sala de coordenação de projetos e reuniões, laboratórios de informática com recursos de hipermídia, sala de tele e videoconferência, salas de aula para encontros presenciais, sala de produção de material impresso e hipermídia (cd-rom, web site, salas virtuais, etc.). A estrutura física do Sead, na Unesc, está sendo implementada de forma gradativa, visando ao atendimento com qualidade dos projetos em andamento e dos futuros, aprovados pelos órgãos de competência da Instituição.

Os recursos tecnológicos listados para esta modalidade devem contemplar sua aquisição e atualização, de acordo com a oferta nesta modalidade. As tecnologias se adequam aos projetos desenvolvidos e atendem aos critérios de qualidade mínimos para a oferta de cursos na modalidade de EaD.

Como recurso de comunicação utiliza-se nos projetos em geral: Ambiente Virtual de Aprendizagem com ferramentas como fórum, chat, conferência on-line e lista de discussão, internet, telefone, fax e correio. No contexto de desenvolvimento que ocorre em parceria com a Diretoria de Informática e Cursos correlatos, busca-se utilizar aplicativos de autoria e edição (texto, vídeo, som e imagem), incluindo tecnologia de produção das aplicações. Os equipamentos disponíveis são: computadores e periféricos (impressoras; webcam, microfones, scaners, gravador de cd-rom); servidores, estrutura de rede de computador; equipamentos diversos como, câmera digital, vídeo, TV, dvd, filmadora, antena parabólica, estrutura para teleconferência e webconferência, projetor de multimídia, TV a cabo e/ou similares; softwares para o ambiente de aprendizagem, ferramentas de comunicação síncrona e assíncrona, softwares de gerenciamento administrativo e pedagógico.

Em cada projeto desenvolvido, são observados estes componentes: de gestão de pessoas, recursos físicos e estrutura tecnológica que se organizam em: Desenho do projeto/programa de acordo com o PPP da IES; Formação de equipe multidisciplinar; Planejamento e organização do projeto; Desenvolvimento do material didático; Formação dos Professores; Organização dos mecanismos de apoio e formação da equipe de apoio; Utilização do AVA da IES; Estrutura física e tecnológica; Sistema de avaliação pedagógica; Sistema de avaliação do processo e de gestão pelo Setor de Avaliação Institucional. A gestão pedagógica e administrativa ocorre de forma compartilhada, no âmbito dos Setores e das Diretorias e Cursos envolvidos nos projetos.

\section{CONSIDERAÇÕES FINAIS}


O modelo proposto, na constituição do Sead em sua inicial informalidade e após sua institucionalização, primou pela construção de um grupo multidisciplinar de estudo, pesquisa e trabalho no contexto de trabalho colaborativo e cooperativo, priorizando os processo de aprendizagem coletiva e a interação social, em contraposição a uma abordagem competitiva, que prioriza o individualismo. Nesse enfoque, cada sujeito contém informações relevantes para o grupo e é visto como membro de uma sociedade que visa a uma melhor interação social entre seus pares. Nesse tipo de processo, são importante as habilidades de troca de conhecimento entre os sujeitos, comprometimento, negociação e entendimento no compartilhamento do problema, além da ajuda mútua em resolvê-lo. Logo todos são aprendizes e podem contribuir um com o outro.

A Unesc preserva esse modelo na gestão do sistema de EaD, gestão essa compartilhada pelas Diretorias e Cursos envolvidos no processo com a assessoria do Sead. Nesse contexto, o trabalho cooperativo e colaborativo representa a construção conjunta do conhecimento num processo de interação e interatividade contínuo, ou seja, em um processo de cooperar e/ou colaborar. A interação e as trocas não se caracterizam apenas pelos aspectos cognitivos, mas também pelos aspectos sociais e perceptuais.

No processo de formação continuada dos professores visando ao fortalecimento da cultura da EaD e a inserção nos cursos presenciais da Instituição, de propostas de utilização de inovações tecnológicas que contribuam com melhorias didáticopedagógicas e que permitam familiarizar o acadêmico com as atuais tecnologias da informação e comunicação, verificou-se também que não é suficiente colocar a tecnologia à disposição dos professores integrantes do grupo e dos projetos.

Também verificou-se que a apropriação dos recursos tecnológicos, as concepções sobre as formas e o conteúdo didático-pedagógico - no contexto presencial e não-presencial - ocorreram em tempos distintos. Portanto é preciso dar espaço e tempo para que, a partir da rede de significados coletiva, cada um desenvolva seu potencial, reflita sobre sua prática e implemente mudanças que possam contribuir no processo educativo na Universidade.

A experiência vivenciada no Sead, nos projetos desenvolvidos em parceria ou próprios, mostra a importância de um planejamento, organização e produção dos materiais no enfoque de um constante repensar, quando esse processo envolve a modalidade de Educação a Distância. Então, estar envolvido numa rede de colaboração auxilia e amplia os significados tanto no contexto de conhecimento quanto no contexto de comunicação.

O que é planejado, organizado e discutido não é apenas utilizado nas produções coletivas dos grupos, mas também nos trabalhos de mudança de prática dos envolvidos.

Apesar das dificuldades detectadas pelo grupo multidisciplinar no processo de construção do Sead, pela necessidade de desenvolvimento de muitas ações e pouco tempo disponível para os estudos, as discussões, as críticas e troca de opiniões que permeiam os processos avaliativos resultaram em bons projetos.

Dentro deste contexto, paralelo a toda esta operacionalização da modalidade, a equipe multidisciplinar busca, também, desenvolver a pesquisa, experimentação e aplicação de propostas pedagógicas/educativas na modalidade de $\mathrm{EaD}$, bem como promover e apoiar a realização de cursos de capacitação em EaD, simpósios, seminários, congressos, encontros, tendo em vista o acesso da comunidade às diversas áreas do conhecimento, na modalidade de Educação a Distância e ainda, em 
âmbito macro, particular parcerias e convênios interinstitucionais para oferta de cursos semi-presenciais e não-presenciais.

Os projetos experimentados e reavaliados pelo grupo multidisciplinar, em parceria e ou individuais, que ocorrem nos âmbitos de Pesquisa, Extensão e PósGraduação lato sensu comprovam que os desafios de implantação de Educação a Distância nas IES representam processos contínuos de avaliação e reavaliação. Essas experiências potencializam outras iniciativas de parceria e individuais.

A relevância desses processos situa-se na importância de participar do desafio de trabalhar com uma modalidade de educação não presencial em uma IES constituída historicamente pela presencialidade. A experiência mostra que, além de contribuir na inserção das tecnologias nas práticas pedagógicas, a presente proposta contribui na formação de grupos multidisciplinares com idéias e concepções coerentes com a modalidade de $\mathrm{EaD}$, fundamentados teoricamente, mas também que vão constituindo-se no processo a partir da reflexão da sua própria prática vivenciada em projetos próprios, em parcerias na IES e nas parcerias interinstitucionais.

\section{REFERÊNCIAS}

LANDIM, Cláudia Maria das Mercês Paes Ferreira. Educação a distância: algumas considerações. Rio de Janeiro: [s.n.] 1997.

MAIA, Carmem. Guia brasileiro de educação a distância. São Paulo: Esfera, 2002. MAIA, Nelly Aleotti; COSTA, Marly de Abreu. Avaliação. In: MARTINS, Onilza Borges (Org.). Curso de formação em educação a distância. Planejamento e gestão em EAD: organização curricular e material didático. Curitiba: UNIREDE, 2001. p.193- 270.

MARTINS, Onilza Borges et al (orgs.). Educação a Distância: um debate multidisciplinar. Curitiba : UFPR, 2001.

NEDER, Maria Lúcia Cavalli. Avaliação na Educação à Distância: significações para definição de percursos. In: PRETI, Oreste (org.) Educação à Distância: Início e indícios de um percurso. Cuiabá : NEAD/UFMT, 2000.

NISKIER, Arnaldo. Educação à distância: a tecnologia da esperança. São Paulo, SP: Loyola, 1999.

OKADA, Alexandra Lilavati Pereira. Desafios para EAD: Como fazer emergir a colaboração e a cooperação em ambientes virtuais de aprendizagem. In: SILVA, Marco (Org.) Educação online: Teorias, práticas, legislação e formação corporativa. São Paulo: Loyola, 2003. p. 273-291.

OLIVEIRA, I.E.A. Didática do Ensino Superior. In: MARTINS, Onilza Borges (Org.). Curso de formação em educação a distância: Metodologia da Pesquisa e Didática do Ensino Superior. Módulo 5, Curitiba: MEC:UNIREDE, 2001. p. 89139.

PERRENOUD, Philippe. Dez novas competências para ensinar. Porto Alegre: Artes Médicas, 2000. UNESC, PRÓ-REITORIA DE ENSINO. Formalização do Setor de Educação a

Distância. Criciúma: Unesc, 2003. 